\title{
The Effect of Learning by the Generative Teaching Strategy on Academic Achievement and Retention of Chemical Concepts in Chemistry for Tenth Grade Students in Busira Directorate of Education Schools
}

\author{
Mr. Ahmad Suleiman Odeh Alqtaishat \\ Jordan - Al-Tafilah
}

\begin{abstract}
The study aimed to investigate the effect of learning by the strategy of generative teaching on academic achievement and retention of chemical concepts in chemistry for tenth grade students in Busira directorate of education schools. The study sample consisted of (62) students distributed in an experimental group (30) students who studied through the generative teaching method and the control one (32) students who studied through the traditional method. The study used the quasi-experimental approach. A guide for the student and teacher to use the generative teaching strategy and an achievement test in the unit consisting of (20) items were prepared The study reached the following results: There were statistically significant differences among the arithmetic means in the post-measurement of achievement in chemistry in favor of the experimental group, and the effect size was $(68 \%)$, and the results showed that there were statistically significant differences among The arithmetic means of the scores of the two groups on the retention test in favor of the experimental group, and the effect size was (70\%). In light of the study results, it was suggested to use the generative teaching strategy in chemistry.
\end{abstract}

Keywords: Generative Teaching, Achievement, Retention of Concepts, Chemistry.

DOI: $10.7176 / \mathrm{JEP} / 12-31-01$

Publication date: November $30^{\text {th }} 2021$

\section{INTRODUCTION}

Science has an essential role in the current society progress by tackling all aspects of life as well as achieving cultural development that is regarded a result of rapid progress of science. It follows that the people interested in science consider the real value if it lies in its ability in interpretation of phenomena and events .This can be attained through fact interaction and correlation in terms of concepts and theories rather than through facts by themselves; the facts without concepts are opaque and the concepts without facts are speculative. (Tamam 1995).

The science teachers are essentially concerned with teaching concepts and scientific principles that represent mental images for the perceptive. These concepts and principles vary due to their different sources as well as the way they are formed. A lot of teachers nowadays are mere exact copies of those who had taught them and follow the same methodology. They also carry the same thoughts in spite of the training they received to teach more effectively instead the traditional methods they were accustomed to. (Windschitl, 1999).

In the present time, science instruction has witnessed more continuous interest and development worldwide and locally. This cause fundamental change in the philosophy and methodology of science teaching to meet today's demands and to promote the education level. This posed difficult task for the educationalists during curricula preparation to keep up with development toward targeted learning such as enhance thinking among students. Such being the case, it is essential to satisfy learner's needs to be able to promote his abilities and skills through different sources of knowledge.

Various changes took place in science teaching programs in the second half of the $20^{\text {th }}$ century. These changes were reflection to economic, scientific and technological shifts and there was need to cope with these changes and adopt new approach in science depending on scientific strategies in research and thinking. ( $\mathrm{Al}$ Hilah, 2002).

It is worth mentioning that the effective instruction is not confined to introduction concepts, facts skills and activities but rather to perform scientific operations on the part of the learner. In that vein, the education specialists have emphasized that one of the most important aims of teaching science is thinking skills development among students by teachers' using of teaching strategies through which students practice activities that trigger thinking and encourage them to ask questions. (Zaitoon, 2004).

On the other hand, science instruction requires adoption new approaches and contemporary as well as new methodology to activate teaching and learning science at different education stages. ( Al Baz, 2001).

As long as grasping students' teaching is primary focus of the process of instruction strategies, there emerge need for identifying the impact of use of teaching strategies on student's learning and their acquisition of scientific concepts as well as their attitudes and beliefs toward science in the light if increasing call to activate 
group learning. This matter obliges teachers to be aware that the change in the education outcomes requires equal change in curricula and methodology and that student's motivation plays essential role in conceptual change. instruction strategies also help students and increase their scientific achievement. (Salmi. 2003).

Constructive teaching is concerned with creation of teaching through construction or reconstruction of mental maps for the individual which are done by mental processes and lead him to modify his cognitive structures so that he can comprehend new experience since it is the cornerstone of individual's knowledge. the learner's cognition is affected by his previous experience which leads to construct new knowledge. The essence of constructive teaching lies in generative teaching strategy based on using mind to construct learner's own explanation of stored information as well as forming inferences through social interactions between learner and teacher.When using generative teaching strategy, it is necessary to provide for teaching situation that enable students to relate the previous learning to the later and allowed him to ask questions, exchange views and criticize thoughts (Abdulsalam, 2006).

\subsection{STATEMENT OF THE PROBLEM AND QUESTIONS}

Various changes took place in science teaching programmers in the $20^{\text {th }}$ century. These changes were reflection to economic, scientific and technological changes and there was need to cope with these changes and adopt new approach in science depending on scientific strategies in research and thinking. (Abdulsalam, 2001)

The researcher, through his practical experience, noticed student's failure and weakness in achievement and retention in scientific and chemical concepts. This was due to students' lack of link between new experiences to the previous ones and not implementing what they learn in real life. Generative teaching strategy was an attempt to solve this problem .Generative teaching strategy include two stages: the primary stage which is concerned with relation new experiences to the previous ones, and application stage which has to do with the student's implementation of everyday skills and experiences they learn. This, in turn, extends the effect of learning for a long time and increase the academic attainment.

This study -generative teaching strategy for retention of chemical concepts and attainment among tenth grade students- is a modest addition to the studies and researches based on constructive learning. It aims to answer the following main question:

What is the impact of learning through generative teaching strategy on attainment and retention of chemical concepts in chemistry for tenth grade students in Busira directorate of education schools?

The main question had the following sub- questions:

1. Were there statistically significant differences at the level $(\alpha=0.05)$ between the control group and experimental group in post- test application of chemistry achievement test?

2. Were there statistically significant differences at the level $(\alpha \leq 0.05)$ in delayed attainment (retention of chemical concept among tenth grade students in chemistry that could be attributed to teaching strategy (generative or traditional teaching)?

\subsection{STUDY SIGNIFICANCE:}

The study is significant in that it is regarded a step toward new strategy improvement and implementation where it is in line with new instructional approaches that require a student to be the engine of the teaching- learning process. The significance of the study is as follows:

1. Its response to the improvement of science teaching process in general and chemistry in particular to achieve the targeted aims in the framework of education development adopted by the Ministry of Education in Jordan.

2. Opening the door to conduct studies dealing with educational materials and variables not adopted in this study. 3. Enriching science teachers in general and chemistry teachers in particular with constructivism- based strategies, thereby they will be helped with well- perpetrated instruction. It shows model classes using generative teaching strategy.

\subsection{PROCEDURAL DEFINITIONS:}

-TEACHING STRATEGY: (Zaitoon,2003) defined it as the planned method of teaching and learning that the teacher follows inside the classroom or outside to teach the content of a particular subject in order to achieve predetermined goals. This approach involves two groups of stages i.e. steps or successive and symmetrical procedures to be followed by the teacher and the students during instruction

-GENERATIVE TEACHING: (Saleh,2000) defined it as a teaching strategy that aims to provide the student with the ability to generate two types of relationships, the first is to generate a relationship between the learner's previous experience and his subsequent experiences, and the second is to generate relationships between parts of knowledge or subsequent experiences to be acquired. In this study, it is represented by linking previous experiences with the subsequent to build chemical concepts in a unit Compounds and chemical bonds from the tenth grade book.

-ACHIEVEMENT: It is the progress made by the learner in learning the unit of compounds and chemical bonds, 
which is represented by the score the learner gets in the achievement test prepared for this study.

-RETENTION: It is the learner's ability to remember the educational material he learns after two weeks of learning, and his ability to retrieve that information from memory, or to identify it when it is raised, measured by his scores on the post achievement test prepared for the unit of compounds and chemical bonds.

-TRADITIONAL TEACHING STRATEGY: It is the common teaching strategy in schools, which is based mainly on oral discussion, and the use of book questions for the purposes of confirming information and emphasizing its cognitive results in addition to evaluation, where the teacher has the greatest role in it.

-CHEMISTRY: It is the textbook for the tenth grade students of the school year 2017/2018 and approved by the Jordanian Ministry of Education according to Education Council Decision No. 50/2005 dated 4/5/2008.

-TENTH GRADE: It is one of the high basic educational stages in which the student's age ranges 15 years, which is one of the divisions of the academic stages of the Jordanian Ministry of Education.

\subsection{STUDY LIMITATIONS:}

The limitations of this study were as follows:

- SPATIAL LIMITS: This study was applied in the schools of Busira Directorate of education.

TIME LIMITS: It was conducted in the second semester of the year 2017/2018.-

HUMAN LIMITS: Tenth grade male students. -

- OBJECTIVE LIMITS: A unit from the chemistry book for the tenth grade, entitled "The Unit of Chemical Compounds and Bonds".

\subsection{THEORETICAL FRAMEWORK AND PREVIOUS STUDIES:}

(Tobin, 1993) indicated that constructivism is a theory of knowledge, and this means that it includes the concept of knowledge, and the images of the relationship among them, and if it is agreed that learning is related to the growth of knowledge and that science is knowledge about specific areas of expertise therefore, constructivism will have complementary relationships with the process of learning and teaching in science.

\section{STAGES OF THE GENERATIVE LEARNING STRATEGY:}

Summarized by (Abu Jalala, 2006):

1- Preliminary stage: The teacher starts with discussion that depends on dialogue and asking questions, and the students respond either with a verbal answer or writing in their notebooks. The common language between the teacher and the student is the psychological tool for thinking, novelty, work, and vision. In this stage, everyday concepts are explored by the teachers through language, writing and work. Its focus is students' individual reasoning towards the concept.

2- The concentric stage: The teacher distributes students in small groups to relate everyday knowledge and target knowledge, and focuses the students' work on the target concepts while presenting scientific concepts, and providing an opportunity for discussion and dialogue among groups, so students experience the concept.

3- Contrasting stage: In this phase, the teacher discusses the whole class with the opportunity for students to make their observations and understanding. He follows the activities of the whole class and help them with appropriate educational and assistance means, with re-introduction of scientific concepts, and the challenge between what the teacher knew in the preliminary stage and what he knew during learning.

4- Application stage: Scientific concepts are used as functional tools to solve problems, find results and applications in new life situations, and help expand the scope of the concept.

\section{KEY FEATURES OF GENERATIVE LEARNING STRATEGY:}

(Al-Najdi, Saudi, Rashid, 2006) indicated to the following features:

1- The students' ideas affect their use of their senses, and therefore the students use the ideas in their cognitive structure in the effective test of the tangible inputs.

2- The concrete input that the student chooses and is interested in does not have a specific meaning by itself, so the students need to be aware that the meaning is something they create, rather than being something that the teacher instills in their minds.

3- The student connects between tangible inputs and knowledge in his cognitive structure.

4- The student uses the links that have been generated and the tangible input in order to form the meaning.

5- The first chooses the meaning that has been reached by comparing it with the meanings in its cognitive structure, or the meanings that have been reached as a result of other sensory inputs.

6- Generating bonds in the student's cognitive structure requires that students assume responsibility for their learning, as all activities undertaken by the student to achieve learning and understanding require his own mental effort.

\subsection{PREVIOUS STUDIES:}

The study of (Al Jaman 2013) aimed to investigate " the effectiveness of generative teaching in retention in 
chemistry and the scientific deduction for ninth grade students " compared to the traditional method before and after conducting the experiment research. The study sample consisted of (61) ninth grade female students from two sections in Al Khaledia secondary school for girls in Western Northern Badia ,directorate , Mafraq. (31) Female students for the experimental group and (30) students for the control group. The experimental group was taught through generative teaching strategy while the control group was taught through traditional method. The study was conducted in the second semester 2012/2013. To achieve the aims of the study. an achievement test in the unit and scientific deduction had been prepared. The results showed that there were statistically significant differences at the level $(0.05=\mathrm{a})$ in the average on ninth grade female students in chemistry retention in favor of the experimental group taught through generative teaching strategy.

The study of (Al Saedeen 2011) aimed to investigate " the effect of the strategy of generative teaching and learning course in tenth grade students' acquisition of the basic concepts of physics and establishing their beliefs toward physics and learning. The study sample consisted of all tenth grade sections in the governments in Al Ramtha directorate. The study sample was (154) male and female students divided into three groups: the first experimental group was taught through generative learning, the second experimental group was taught through learning course, and the third control group studied through traditional method. To achieve the aims of the study, a test for physical concepts acquisition was administered to the tenth grade students. The results showed that there were statistically significant differences among the averages of physical concepts acquisition for the students in favor of generative learning strategy compared to the learning course and traditional method and this was attributed to the teaching strategy.

the study of (Daheer 2009) conducted a study aiming to identify the impact of using generative learning in the treatment of alternative perceptions for mathematical concepts among eighth grade students. The study sample consisted of (72) students who were divided into two groups: an experimental group who studied through generative learning, and a control group who studied in traditional method. The study results showed the effectiveness of generative learning for the eighth grade students. It also showed there were statistically significant differences among the averages of the students' scores in the two post groups in favor of experimental group and that was ascribed to generative learning strategy.

(Salehstudy 2009) aimed to detect the effect of generative learning model in developing some science and achievement operations in the physics for the first secondary students in Saudi Arabia. The study used the experimental methodology which was based on experimental treatment- design. The study sample was chosen from (90) first secondary students. The sample was divided into experimental group (44) students and a control group (45) students. the researcher used difficulty and discrimination coefficients for achievement- test items. The study results showed that there were differences in post application between the two groups in favor of experimental group that studied the same units (heat and thermal expansion) in traditional method.

\subsection{METHODOLOGY:}

The study used quasi-experimental approach to cover the application aspect, answer its questions and to elicit results depending on measurement tools designed for the purposes of this study according to commonly accepted procedures.

\subsection{STUDY INSTRUMENT:}

An achievement- test in material unit in tenth grade chemistry book was developed .It consisted of (20) multiplechoice items and every student had to choose one correct answer out of four choices.

\section{STUDY VARIABLES:}

\subsection{THE PRESENT STUDY INCLUDED THE FOLLOWING VARIABLES:}

1- THE INDEPENDENT VARIABLE: it represented in teaching strategy and it had two types (traditional teaching method and generative teaching strategy).

2- THE INDEPENDENT VARIABLE: it is represented in students' achievement- test and retention of the chemical concepts. It was measured through study sample's answers to the achievement- test.

\subsection{STUDYSAMPLE:}

The study sample consisted of tenth grade students from Al Tafilah Governorate schools in the academic year 2017/ 2018. the study sample was chosen in purposive method from Quadisiah secondary school for boys, Busira .Two tenth grade sections out of four sections were chosen. The number of the two sections was (62) students, (30) of them studied through generative teaching method and (32) students learned through traditional method.

\subsection{STATISTICAL TREATMENT:}

Statistical treatment had been carried out using SPSS (Statistical Package for the Social Sciences) to assess the 
study results as follows:

1. The arithmetic means and standard deviations for responses of the study sample individuals to the achievement- test of each group.

2. ANCOVA (Analysis of Covariance) to examine the differences among the groups in post application of the achievement- test.

3. Eta squared to measure the size effect.

4. Kuder - Richardson 20 to verify the reliability of the achievement- test.

5. Difficulty and discrimination coefficients

1. Were there statistically significant differences at the level $(\alpha=0.05)$ between the control group and experimental group in post- test application in chemistry achievement test?

To answer the question, the researcher used (ANCOVA) between the control group and experimental group to compare the performance level in post-measurement of achievement - taking into consideration that the achievement level of post- measurement was the covariate variable (control variable) as shown in the tables (3) and (4).

Table (3): Arithmetic means of tenth grade students' achievement in chemistry.

\begin{tabular}{rccccc} 
Group & \multicolumn{2}{c}{ pre measurement } & \multicolumn{2}{c}{ post measurement } & \multicolumn{2}{c}{ adjusted } \\
arithmetic & standard & arithmetic & standard & arithmetic \\
mean & deviation & mean & deviation & 2.49 & 11.26 \\
control & 4.38 & 1.79 & 10.88 & 1.91 & 16.06
\end{tabular}

Table (4): One-way analysis of variance (ANCOVA) to examine the differences between achievement groups in chemistry in the post-measurement

$\begin{array}{rccccc}\begin{array}{r}\text { Source of } \\ \text { variance }\end{array} & \begin{array}{r}\text { sum of } \\ \text { squares }\end{array} & \begin{array}{r}\text { degree of } \\ \text { freedom }\end{array} & \begin{array}{r}\text { mean } \\ \text { squares }\end{array} & \text { (F) value } & \begin{array}{r}\text { level of significance } \\ \text { size effect } \\ \text { (ETA } \\ \text { between }\end{array} \\ \begin{array}{r}\text { groups } \\ \text { Error }\end{array} & 332.809 & 1 & 332,809 & 122.427 & 0.00 \\ \text { Total } & 12216.000 & 62 & 2.718 & & 68 \% \\ \text { Adjusted } & 781.097 & 61 & & & \\ \end{array}$

Data in table (3) indicated that there were statistically significant differences at the level $(\alpha=0.05)$ between the means of post- measurement of achievement in chemistry according to the group variable (control, experimental) after controlling the post- performance. By reference to the adjusted arithmetic means, it appeared that the mean of control group members' performance was (11.26) and the mean of experimental group members' performance was (16.06). This Indicated that the differences were in favor of the experimental group and the results promoted the fact that generative teaching strategy had effect on tenth grade students' achievement in chemistry. According to Coheen's classification, the calculated size effect which was $(68 \%)$ assured that there was great effect of generative teaching strategy on tenth grade students' achievement in chemistry.

Figure. (2): shows the variance between the control and experimental group in the post application of chemistry test after adjusting the pre-measurement.

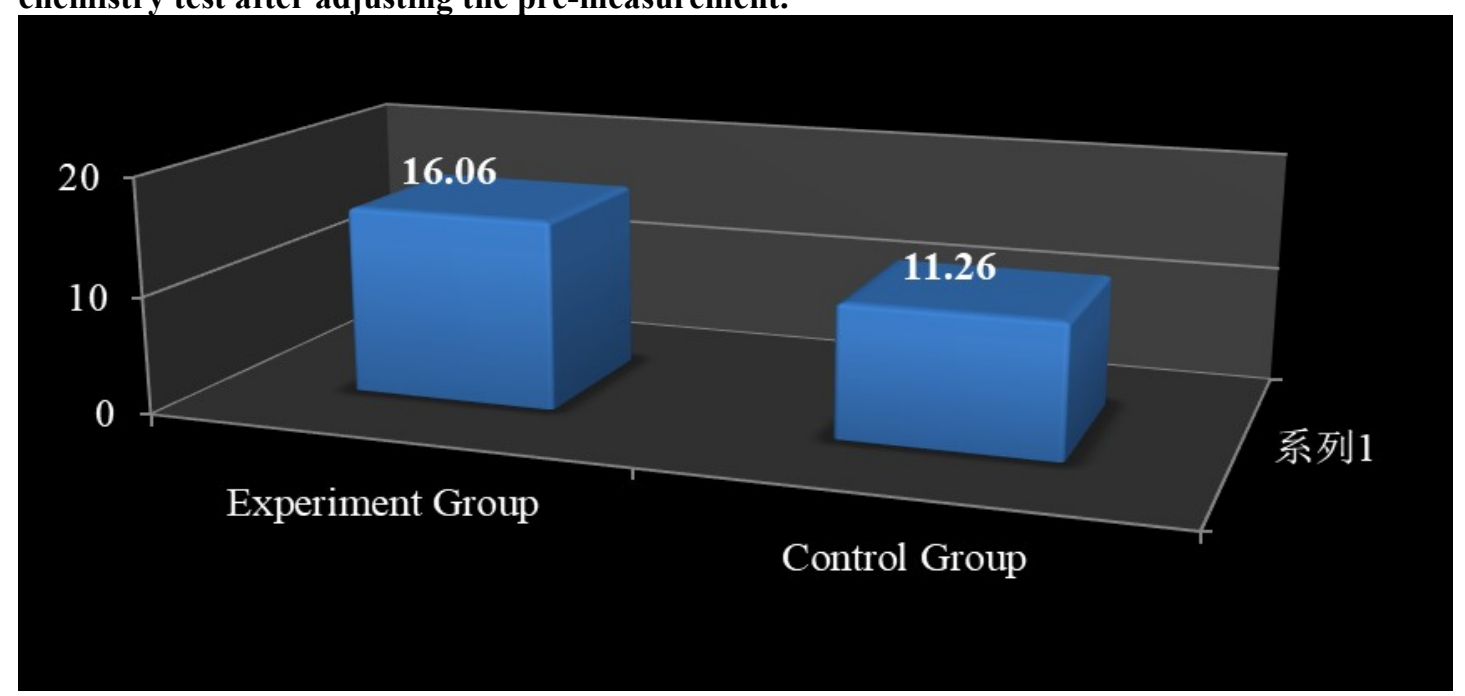


2. The results related to second question of the study stating that:

Were there statistically significant differences at the level $(\alpha \leq 0.05)$ in delayed achievement (retention of chemical concepts) for the tenth grade students in chemistry that could be attributed to teaching strategy (generative or traditional teaching)?

To answer the question, the researcher used (ANCOVA) between the control group and experimental group to compare the performance in delayed - measurement taking into consideration that the achievement of postmeasurement was the pre- variable (control variable) as shown in the tables (5) and (6).

Table (5): Arithmetic means of tenth grade students' achievement in chemistry in the post and delayed measurements.

\begin{tabular}{cccccc} 
Group & \multicolumn{2}{c}{ post measurement } & \multicolumn{2}{c}{ delayed measurement } & adjusted arithmetic \\
& $\begin{array}{c}\text { arithmetic } \\
\text { mean }\end{array}$ & $\begin{array}{c}\text { standard } \\
\text { deviation }\end{array}$ & $\begin{array}{c}\text { arithmetic } \\
\text { mean }\end{array}$ & $\begin{array}{c}\text { standard } \\
\text { deviation }\end{array}$ & mean \\
$\begin{array}{c}\text { Control } \\
\text { Experimental }\end{array}$ & 10.88 & 2.49 & 7.13 & 1.60 & 8.81 \\
& 16.47 & 1.91 & 16.10 & 1.97 & 14.30
\end{tabular}

Table (6): Variance Analysis (One-way ANCOVA to examine the differences between achievement groups in chemistry in the delayed measurement

$\begin{array}{rcccccc}\begin{array}{r}\text { Source of } \\ \text { variance }\end{array} & \begin{array}{c}\text { sum of } \\ \text { squares }\end{array} & \begin{array}{c}\text { degrees of } \\ \text { freedom }\end{array} & \text { mean squares } & \text { (F) value } & \begin{array}{c}\text { Level of } \\ \text { significance }\end{array} & \begin{array}{c}\text { size effect } \\ \text { (ETA } \\ \text { squared) }\end{array} \\ \text { between groups } & 177.411 & 1 & 177.411 & 136.245 & 0.00 * & 0.70 \\ \text { error } & 76.827 & 59 & 1.302 & & & \\ \text { total } & 9593.000 & 62 & & & \\ \text { adjusted total } & 1439,435 & 61 & & & & \\ \end{array}$

Data in table (5) indicated that there were statistically significant differences at the level $(0.05 \geq a)$ between the means of the delayed achievement in science according to the group variable (control, experimental) after controlling the performance in post- measurement, by reference to the adjusted arithmetic means, it appeared that the mean of control group members' performance was (8.81) and the mean of and the mean of experimental group members' performance was (14.30). This indicated that the differences were in favor of the experimental group and such result promoted the fact that generative teaching strategy had effect on tenth grade students' retention in chemical concepts as well as in chemistry achievement.

According to Coheen's classification, the calculated size effect which was (70\%) assured that there was great effect of generative teaching strategy on tenth grade students' achievement and retention of chemistry.

\subsection{DISCUSSION:}

1. Discussion of the results related to the first question which stated that: Were there statistically significant differences at the level $(0.05=$ a) between the control group and experimental group in posttest application in science achievement test?

The results showed that there were statistically significant differences between the means of the two groups (experimental and control) regarding the post-measurement of achievement in chemistry and in favour of the experimental group. This indicated that there was an impact of the generative teaching strategy in the tenth grade students' achievement in chemistry. The size effect (68\%) emphasized the great impact of this strategy. The researcher explained this result according to the fact that the mental correlations of chemistry concepts established by the students who learned through this strategy had effect on their scores. He also added that teaching through this strategy helped students relate what they hear, see and read by constructing relationship among these senses as well as coordination of sight, hearing and articulation, which facilitated establishing relation which in turn facilitated students' realization and acquisition of concept. as a consequence, it had been reflected on their achievement in chemistry characterized by difficult concepts. Generative instruction strategy according to the researcher - make it easy for tenth grade students to acquire the rigid of chemistry concepts due to its multiple strategies combined together and achieved the expected result which was formation of conceptions of science concepts by acquiring new concepts and relating them to their previous outcome of these concepts. This result is also explained based on the fact that the learner is the focus of this strategy, so it is consistent with the results of the study of(Al Jaman 2013) in which there were statistically significant differences in the average of the ninth grade female students' achievement in chemistry. This was due to the teaching model and in favor of the experimental group which studied through generative teaching strategy and the study of (Al Saedeen 2011) whose results referred to statistically significant differences between the means of physical concept- acquisition attributed to the strategy of teaching, and in favor of the strategy of generative learning . The study of (Daheer 2009) which came with the results: the effectiveness of generative learning among the eighth 
grade students and the existence of statistically significant differences between the average scores of the students in the two post-test groups in favor of the experimental group due to the generative learning strategy. The study of (Kourilsky 2004) whose results indicated that the use of the generative teaching strategy in instruction was effective and positive. The study of (Muhammad, 2003) showed that the generative model in teaching has a great influence and effect in modifying the alternative perceptions about frightening natural phenomena and it also had great influence and effectiveness in students' acquisition of the scientific deduction skills , thus this result contradicted the study of (Saleh, 2009) whose results showed that there were differences in the postapplication between the two groups in favor of the experimental group that studied the same units (heat and the expansion of objects by heat) in the traditional method.

2. Were there statistically significant differences at the level $(\alpha \leq 0.05)$ in delayed achievement (retention of chemical concepts) for the tenth grade students in chemistry that could be attributed to teaching strategy (generative or traditional teaching)?

The results showed that there was a statistically significant difference between the means of both groups' scores (control and experimental) on the delayed achievement test (retention of chemical concepts) in chemistry in favor of the experimental group. This demonstrated the effectiveness of the generative teaching strategy in the tenth grade students' retention of learning material that was implemented in accordance with the generative teaching strategy. The researcher attributed this result to the fact that education in this strategy has developed the skill of thinking, recalling and retention among students. The researcher also ascribed this result to the fact that teaching through this strategy facilitated students' acquisition of chemistry concepts and helped them establish relations among these concepts compared the control group learning through traditional method and whose performance didn't develop regarding delayed achievement test where their achievement test results didn't improve. This is evidence that traditional method was not effective as far as thinking development and retention was concerned, and the student was not able to establish relations among concepts so that he could keep and recall the learned material.

This result might be attributed to the impact of the generative teaching strategy in facilitating the transfer of learning effect. This result may be attributed to the social and dynamic atmosphere and interaction between the chemistry teacher and the students. This facilitated the acquisition, retention and recall of the concepts when needed (delayed test).The researcher also accounted for this result in that students' retention and easy recall of concepts - compared to the control group's lack of exposure to such experiences -were enhanced by discussing lesson concepts, allowing them reintroduce their notes, expressing what they understand, discussing lesson activities, using appropriate teaching aids, recycling concepts, relating the stages of this strategy.

This result might be attributed to the fact that teaching by this strategy had helped students to retrieve the concepts of chemistry. It was as well due to the effectiveness of this strategy in helping students to remember previous concepts and relate them to current knowledge. This enabled student to retain concepts and call them during the delayed test. It may be attributed to the repetition of concepts during the application of generative teaching stages that enabled students to understand and retain concepts as well as their ease of retrieval.

\subsection{RECOMMENDATIONS:}

Based on the findings of the study, the following recommendations can be made:

1. Teaching chemistry in the secondary stage, especially in the final stage (second secondary), with the generative strategy for its ability to help students retain concepts and recall them during tests.

2. Involving students in the process of learning concepts of science in general and concepts of chemistry in particular, and help them focus on finding one correct answer.

3. Conducting more research and studies on the impact of this strategy in educational stages and other directorates of education to benefit from its results and generalizations.

4. Reconsidering the methods of teaching chemistry at the high basic stage to keep pace with developments, scientific progress in the field of chemistry and development in learning and teaching theories.

5. Investing in the learner's activity and its advantages, and his participation in activities and scientific experiments in a way that makes him able to generate, produce and retain new concepts and easily recall them.

\section{REFERENCES}

-Albaz, Khaled. (2001) the effectiveness of using Marzano's dimensions of learning model in teaching chemistry on achievement, compound thinking, and attitude toward chemistry among first secondary students in Bahrain. The fifth scientific conference: scientificcitizenship education from 29/7/2001, Egyptian society for scientific education volume 2. Cairo: Ain Shams University

-Tammam. Tammam Ismael . (1995) the effect of using learning course in teaching scientific concepts contained in the subject of light for the first preparatory students. Faculty of education journal - Assiut University 2 (2) 565,593

-Al Jaman, Sana . 2013. the effectiveness of generative teaching in achievement in chemistry and the 
scientific deduction for ninth grade students. Unpublished Master's thesis, , Al Albayt University Jordan. -Al Hilah, Mohammed (2002) education design a theory and practice, Amman, Dar Al Maseera

-Zaitoon , Kamal. (2004) teaching science to understand - constructive vision, volume 2, Cairo : Alam Al Kotob

-Al Saedeen, Hussein.( 2011)" the effect of the strategy of generative teaching and learning course in tenth grade students' acquisition of the basic concepts of physics and establishing their beliefs toward physics and motivation toward learning, unpublished doctoral dissertation, Yarmouk University, Jordan.

-Saleh, Medhat Mohammed Hassan : (2009), Cairo the effect of generative learning model in developing some science and achievement operations in physics for the first secondary students in Saudi Arabia, 21st scientific conference, curricula development between originality and Modernity

-Daheer, Khaled (2009). The impact of using generative learning in the treatment of alternative perceptions for mathematical concepts among eighth grade students. Unpublished Master's thesis, Islamic University, Gaza, Palestine

-Abdulsalam, Abdulsalam, (2006) the new approaches in teaching science, Dar Al Feker Al Arabi. Cairo.

-Salmi, H. (2003).science centers as learning laboratories: Experiences of Eureka. International journal of Technology Management.25(5):460 -476.

-Windscchitl، M. (1999). Framing constructivism in practice as the negotiation of dilemmas: An analysis of the conceptual pedagogical cultural, and political challenges facing teachers .of Educational Research,72(2),131 - 175.

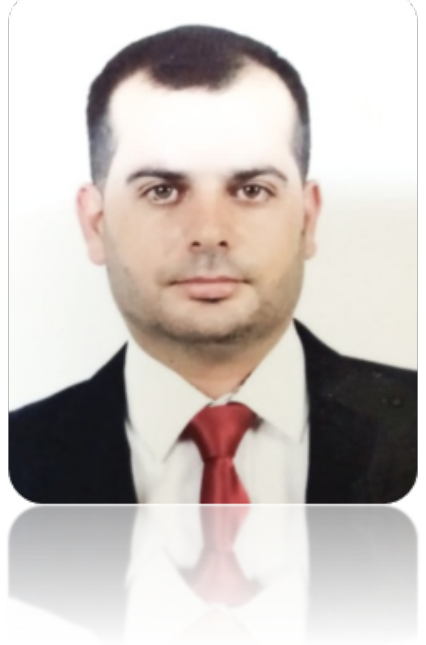

\author{
Mr. AHMAD SULEIMAN ODEH ALQTAISHAT
}

JORDAN - AL-TAFILAH 